\title{
Proceedings of the meeting of the Society of British Neurological Surgeons, London, April 1991
}

RUPTURED INTRACRANIAL ANEURYSMS: WHERE DO WE GO FROM HERE?

RS Maurice-Williams. London

Even with modern methods of treatment, many patients do badly after rupture of an intracranial aneurysm. The reasons for unsatisfactory outcome were examined in a series of 400 consecutive patients treated over 13 years (June 1977-February 1990). There were changes in treatment over this period, but an "open door" admissions policy was maintained throughout, meaning that the untreated prognosis should have remained constant. Over successive 100 patient cohorts, management mortality fell steadily from $38 \%$ to $24 \%$. A detailed analysis of the reasons for poor outcome suggested that changes in management within the constraints of the currently available methods of treatment would probably have little effect on overall outcome. Most patients who did badly after surgery did so either because of preexisting neurological damage or because of some technical difficulty at the time of operation itself.

FACTORS AFFECTING OUTCOME AFTER ANEURYSMAL SUBARACHNOID HAEMORRHAGE WAS Taylor, R Bullock, P Harries. Glasgow

Over the past five years, neurosurgical management of patients with subarachnoid haemorrhage has changed considerably. For example, the use of calcium antagonists has become routine, and Glasgow, in common with many other centres, has introduced early surgery. To assess the effect of changing patterns of management on the outcome of patients with aneurysmal subarachnoid haemorrhage (SAH) a consecutive series of 296 patients with angiographically demonstrated aneurysms managed during a three year period (1986-1988) were reviewed retrospectively. Two hundred and seventy five patients from this selected series came to craniotomy after their first SAH. Twenty three patients $(8 \%)$ were not offered surgery because of poor medical or neurological condition. Fifteen clinical, radiological, operative and post operative variables were studied and their association with outcome (Glasgow outcome scale), was tested using univariate analysis.

The overall mortality rate was $9.4 \%$ and for those operated upon was $4 \%$. Factors significantly associated with a poor outcome (dead, vegetative or severely disabled) were: WFNS Grades III-V; presence of a haematoma on the first CT scan; presence of a post-operative haematoma which required surgery; unwanted hypoxia during surgery; delayed ischaemic neurological deficit; and hydrocephalus requiring drainage.

Factors which did not significantly correlate with outcome included: age $>65$ years ( 19 patients, $7 \%$ of the series); timing of the surgery $(20 \%$ were operated upon within five days of SAH); angiographic spasm; intraoperative aneurysm rupture $(20 \%)$; use of temporary clipping, and grade of the operating surgeon. Delayed ischaemic deficit occurred in 82 patients ( $32 \%$ ) but $76 \%$ made a favourable recovery.
These results compared favourably with those reported in the recent International Study $^{1}$ (14\% surgical mortality rate). A policy of selective early surgery, prophylactic Nimodipine therapy, and vigorous ICU treatment of ischaemic deficit appears to offer the best prospect for improving outcome after aneurysmal SAH. Evidence from this study suggests that more patients in Grades IV and $V$ may benefit from admission and neurosurgical management ( $68 \%$ of 28 patients making a favourable outcome)

\section{Kassell NF. J Neurosurg 1990;73:37-47.}

POSTERIOR CEREBRAL ARTERY ANEURYSMS-A DIFFERENT APPROACH

CJ Gerber, G Neil-Dwyer. Southampton

Posterior Cerebral artery (PCA) aneurysms are uncommon, constituting up to $2 \cdot 2 \%$ of all intracranial aneurysms. ${ }^{1}$ Conventionally, PCA aneurysms are approached by either the subtemporal or pterional approaches depending on their location. ${ }^{\prime}$ Recently a basal approach to the middle cranial fossa has been developed which gives excellent access to the region of the perimesencephalic cisterns. ${ }^{2}$ This approach had recently been used in the surgery of PCA aneurysms in Southampton. Since 1965 there had been 15 patients $(0.7 \%$ of all patients having angiography for SAH) who had a PCA aneurysm demonstrated angiographically. The anatomy of the aneurysm was well shown by the axial radiological projection.

Ten patients had undergone surgery with no operative mortality. The transzygomatic approach was used in three. Nine patients had made a good recovery and one patient remained moderately disabled.

The authors considered that the transzygomatic approach resulted in unrivalled access to the free edge of the tentorium and to the interpeduncular and perimesencephalic cisterns and recommended its use for proximal PCA aneurysms. The distal P4 aneurysms should be approached by occipital craniotomy.

1 Drake CG. Prog Neurol Surg 1978;9:122-94. 2 Neil-Dwyer G, Sharr M, Haskell R, Currie D, Hosseini M. Neurosurgery 1988;23:20-22.

\section{DO ENDOTHELIN-1 (ET-1) AND HUMAN}

BIG-ENDOTHELIN (b-ET) CAUSE SUBARACHNOID HAEMORRHAGE?

AHS Huneidi, C Thiemermann, PS Lidbury, EE Anggard, JR Vane, F Afshar. St Bartholomew's Medical College, London

Endothelin-1 (ET-1) is a potent vasoconstrictor peptide found in various mammals including humans. ${ }^{1}$ Its precursor, bigendothelin (b-ET) can be activated by polymorphonucleocytes. ${ }^{2}$ The authors reported that ET-1 and b-ET produced subarachnoid haemorrhage in the anaesthetised New Zealand white rabbit. Systemic administration of ET-1 ( $1 \mathrm{nmol} / \mathrm{kg} ; \mathrm{n}=8)$ or b-ET ( $3 \mathrm{nmol} / \mathrm{kg} ; \mathrm{n}=8$ ) produced a substantial rise in the left ventricular systolic pressure (LVSP) and caused subarachnoid haemorrhage (SAH) in $75(17 \%)$ and $87.5(12 \%)$ of the experiments respectively $(p \leq 0.05)$. The cyclo-oxygenase inhibitor indomethacin ( $5 \mathrm{mg} / \mathrm{kg}$ iv) potentiated the pressor effect of both peptides. Groups pretreated with indomethacin before ET-1 $(n=3)$ or b-ET $(\mathbf{n}=3)$ developed SAH. Control animals treated with vehicle (saline; $\mathbf{n}=7$ ), the carboxy-terminal of b-ET (CT 22-38; $3 \mathrm{nmol} /$ $\mathrm{kg} ; \mathbf{n}=3$ ), or indomethacin alone $(\mathbf{n}=3)$ developed neither rise in LVSP nor SAH. A rise in blood pressure alone is unlikely to account for the SAH encountered with ET-1 and b-ET as angiotensin II (AII; $1 \mathrm{nmol} / \mathrm{kg}$ / $\min$ for $30 \mathrm{~min} ; \mathrm{n}=\mathbf{8}$ ), produced a larger increment in LVSP but did not cause any SAH. Furthermore, there was no significant correlation between the rise in LVSP produced by ET-1 or b-ET and the severity of the haemorrhage.

1 Yanagisawa M. Nature 1988;332:411-15.

2 Sessa W. J Cardiovasc Pharmacol 1991 (In press).

ARTERIO-VENOUS MALFORMATION OF THE TRANSVERSE DURAL VENOUS SINUS IC Bailey, BG Mathew. Belfast

Arterio-venous malformations (AVM) involving the transverse dural sinus make up $10 \%$ of all intracranial AVMs. In recent years, the pathophysiology of this condition has become better understood and there are strong suggestions that this type of AVM may be an acquired rather than a congenital lesion. Occlusive thrombosis of the sinus (associated with trauma, infection, surgery, meningioma, cerebral AVM) can often be demonstrated which gives credence to the theory that the AVM is the result of dilatation of A/V shunts between the feeding arteries, derived mainly from the external carotid artery, and the transverse sinus or the cortical veins.

The presenting features vary with different clinical syndromes being described. These range from a complaint of tinnitus to the development of a raised ILP and a massive intracerebral haemorrhage. Therapeutic failure was common in the past as it was only thought necessary to ligate the feeding arteries. It is now believed that complete excision of the lesion is needed to bring about a complete cure. The Belfast experience was reviewed of four patients (three operations) with good recoveries. Glasgow Outcome Scale.

ARE INTRACRANIAL ANEURYSMS ASSOCIATED WITH CERTAIN HLA ANTIGENS? D Rawluk, K Poulton, K Chishti, P Pandya, D Sandeman, RD Page, K Hussain, PA Dyer, RH Lye. Manchester

An increased frequency of the HLA-DR2 antigen in patients with intracranial aneurysms has been demonstrated and cited as evidence of a genetic predisposition for aneurysm development. ${ }^{1}$ This is disputed. ${ }^{2}$ HLA antigens were determined in an aneurysm population using standard methods and frequencies ( $f$ ) compared with controls. Only insignificant trends were observed (table). The HLA-DR2 antigen was evenly distributed (total aneurysm group: $f=23.2 \%$; controls: $f=29 \cdot 8 \%$ ) 


\begin{tabular}{|c|c|c|c|c|}
\hline Aneurysm group (n) & $H L A$ antigen & Group $f(\%)$ & Control* $f(\%)$ & p† \\
\hline All aneurysms (155) & DR1 & 12.9 & $20 \cdot 8$ & $0.016 \mathrm{NS}$ \\
\hline Anterior cerebral (57) & $\begin{array}{l}\text { DR7 } \\
\text { B8 } \\
\text { B15 } \\
\text { B35 } \\
\text { DR1 }\end{array}$ & $\begin{array}{l}32 \cdot 9 \\
14 \cdot 0 \\
21 \cdot 1 \\
21 \cdot 1 \\
10 \cdot 5\end{array}$ & $\begin{array}{l}24 \cdot 2 \\
27 \cdot 1 \\
10 \cdot 9 \\
11 \cdot 5 \\
20 \cdot 8\end{array}$ & $\begin{array}{l}0.022 \\
0.019 \mathrm{NS} \\
0.027 \mathrm{NS} \\
0.038 \mathrm{NS} \\
0.041 \mathrm{NS}\end{array}$ \\
\hline $\begin{array}{l}\text { Middle cerebral (39) } \\
\text { Internal carotid (47) }\end{array}$ & $\begin{array}{l}\text { B14 } \\
\text { A3 } \\
\text { B13 } \\
\text { DRw6 } \\
\text { DR7 }\end{array}$ & $\begin{array}{r}18.0 \\
14.9 \\
12.8 \\
8.5 \\
40.4\end{array}$ & $\begin{array}{r}7 \cdot 8 \\
28 \cdot 2 \\
4 \cdot 0 \\
21 \cdot 2 \\
24 \cdot 2\end{array}$ & $\begin{array}{l}0.037 \text { NS } \\
0.032 \text { NS } \\
0.017 \text { NS } \\
0.023 \text { NS } \\
0.014 \text { NS }\end{array}$ \\
\hline
\end{tabular}

$\star_{n}=504, \dagger$ Fisher's exact test, $2 \times 2$ table, NS: not significant when adjusted for no. of tests.

The authors failed to demonstrate a link between possession of a specific HLA antigen(s) and the presence of an intracranial aneurysm except for multiple aneurysms with a preponderance of Bw62.

1 Ostergaard JR, Bruun-Petersen G, Lamm LU. Tissue Antigens 1986;28:176-81.

2 Schievink WI, De Waal LP, Hageman LM, et al.

J Neurol, Neurosurg, Psychiatry 1988;51:883.

SEVERE HEAD INJURIES IN BRITISH NEUROSURGICAL UNITS: INITIAL SEVERITY, MANAGEMENT AND OUTCOME

G Teasdale, L Murray, G Murray, B Jennett, JD Miller, MDM Shaw, JD Pickard Glasgow, Edinburgh, Liverpool and Southampton

Variations in methods of intensive care of head injuries reflect doubts about the effect on outcome of certain components of management. In a study of prognosis and outcome, data were collected prospectively on 988 patients admitted to one of four British neurosurgical units within three days of a severe head injury-defined as resulting in coma (no eye opening, no comprehensible verbal response and not obeying commands).

Many of the features of the patients in the four centres were similar but interesting differences were found. There was a four fold variation in the annual incidence in different centres: from two to nine cases per 100000 and a two fold variation in the proportion of injuries due to an alcoholic fall ( $9 \%$ to $22 \%$ ). There were variations in the speed of admission to neurosurgery, in patients' ages and initial severities. There were also marked variations in the employment of different aspects of management (table 1).

Table 1 Management in neurosurgical unit

\begin{tabular}{llll}
\hline Centre & $\begin{array}{l}\text { ICP } \\
\text { Measured }\end{array}$ & Osmotics & Ventilation \\
\hline A & $33 \%$ & $17 \%$ & $51 \%$ \\
B & $55 \%$ & $53 \%$ & $77 \%$ \\
D & $1 \%$ & $11 \%$ & $68 \%$ \\
\hline
\end{tabular}

The outcomes in the four centres are shown in table 2.

Table 2 Outcome at six months

\begin{tabular}{llll}
\hline Centre & $\begin{array}{l}\text { Dead/ } \\
\text { vegetative }\end{array}$ & $\begin{array}{l}\text { Severe } \\
\text { disability }\end{array}$ & $\begin{array}{l}\text { Moderate/ } \\
\text { good }\end{array}$ \\
\hline A & $38 \%$ & $17 \%$ & $45 \%$ \\
B & $44 \%$ & $10 \%$ & $47 \%$ \\
C & $45 \%$ & $20 \%$ & $35 \%$ \\
D & $34 \%$ & $23 \%$ & $41 \%$ \\
\hline
\end{tabular}

Mortality in the centres with the more aggressive, interventionist approach was moderately reduced in the better prognosis cases.
INCREASED INTRACRANIAL BLOOD FLOW VELOCITY AFTER SEVERE BRAIN INJURY: A TRANSCRANIAL DOPPLER STUDY

KH Chan, JD Miller, NM Dearden, S Midgley. Edinburgh

Transcranial Doppler was used to examine the relationship between increased intracranial blood flow velocity and changes in intracranial haemodynamics and subsequent development of cerebral infarction in 50 patients with severe brain injury (admission Glasgow Coma Score $\leqslant 8$ ). Forty one patients had intracranial pressure monitoring and $22 \mathrm{had}$ in addition continuous recording of jugular bulb venous oxygen saturation (SJO2). CT was performed on admission and serially thereafter. Blood flow velocity of at least both middle cerebral arteries (MCA) were obtained daily and continuous MCA velocity recording was carried out during changing cerebral perfusion pressure (CPP).

Seventeen patients (34\%) developed increased MCA velocity (mean $>100 \mathrm{~cm} / \mathrm{s}$ ), which was observed only when CPP exceeded $60 \mathrm{mmHg}(p<0.0001)$. Of these 17 cases, six had global hyperaemia (arteriorvenous oxygen content difference $<4 \mathrm{ml} / \mathrm{dl}$ ) and they had bilateral increased MCA, anterior (ACA) and posterior cerebral artery (PCA) velocity. The remaining 11 patients had unilateral $(\mathbf{n}=9)$ or bilateral $(\mathbf{n}=1)$ increased MCA velocity and one had unilateral increase of MCA, ACA and PCA velocity. Noncontusion related low density lesions (NRI) were noted on follow up CT in four of the 11 nonhyperaemic patients in the territory of vessels with increased velocity but none in the remaining 39 patients $(p<0.01)$. Among the nonhyperaemic patients with increased velocity, all with NRI required therapy to restore compromised CPP compared with one out of five without NRI ( $p<0.05)$.

In conclusion, development of increased velocity is dependent upon CPP. Concomitant SJO2 monitoring allows elimination of increased velocity due to hyperaemia which has a different pattern of velocity increase. Increased velocity in a nonhyperaemic patient probably signifies vasospasm. The combination of reduced CPP and vasospasm is associated with an increased risk of infarction.

CONTINUOUS MONITORING OF CEREBRAL AUTOREGULATION: EXPERIMENTAL AND THEORETICAL ASPECTS OF PULSATILE INTRACRANIAL HAEMODYNAMICS

RJ Nelson, M Czosnyka, W Maksymowicz, S Perry, JL Martin, JD Pickard. Bristol; Warsaw; Southampton

Continuous monitoring of CBF autoregulation may help to manage patients at risk of cerebral ischaemia and allow treatment to be directed at differing pathophysiological disturbances including raised ICP due to impaired cerebral vasomotor responses.
Theoretical considerations suggest that the pulse amplitude of cerebral blood flow velocity (FVamp) will be inversely related to cerebrovascular resistance (CVR) and may thus be used as an indirect index of CSF autoregulatory changes.

The authors examined changes in FVamp and mean FV (8 Mhz pulsed transcranial Doppler ultrasound, TCD), cortical CBF $\left(\mathrm{H}_{2}\right.$-clearance) and cerebral perfusion pressure (CPP) during intracranial hypertension and systemic hypotension in normal rabbits and subarachnoid haemorrhage rabbits with impaired autoregulation. A two-slope relationship was observed between the FVamp and CPP with a breakpoint which coincided with the lower limit of CBF autoregulation of each animal. Below the breakpoint, FVamp varied directly with CPP and above the breakpoint FVamp varied inversely with CPP. The relationship between FVamp and CPP and the exhaustion of antoregulatory capacity were continuously monitored by computation of a floating correlation coefficient, RFVamp/CPP.

Simultaneous recording of FVamp, CPP and RFVamp/CPP may be a means of monitoring CBF autoregulation in clinical practice.

CONTINUOUS POST-OPERATIVE MONITORING OF CEREBRAL BLOOD FLOW USING THERMAL

CLEARANCE, AS A PREDICTOR OF CORTICAI ISCHAEMIA

MS Choksey, IR Chambers, AD Mendelow, HA Crockard, A Clark, A Green, DT Delpy. Newcastle and London

In subarachnoid haemorrhage, cerebral blood flow (CBF) may fall below critical levels. CBF measurement has been available for nearly 50 years, but established clinical indications for its use are few, perhaps because there is no widely accepted method for continuous CBF monitoring.

The thermal clearance of tissues is closely related to their blood flow. ${ }^{1}$ The authors have developed an implantable probe, enabling continuous monitoring of the thermal clearance of the cerebral cortical surface postoperatively, measured in $\mathrm{mJ} \cdot \mathrm{cm}^{-1} \cdot \mathrm{s}^{-1} \cdot{ }^{\circ} \mathrm{C}^{-1}$ (henceforward referred to as Clearance units. Zen flow studies recorded a value of 24-27 Clearance units. It had been used in 12 patients, all of whom had undergone clipping of anterior circulation aneurysms. In nine patients the thermal clearance stayed consistently high, and stable (45-54 Clearance units): all made uneventful recoveries.

In the three remaining patients consistently low post-operative thermal clearances (38-45 Clearance units) were noted. These clearances later fell to 32-35 Clearance units. Between one to 24 hours after these falls were noted, the patients developed clinical evidence of ischaemic complications.

Thus a group of patients had been identified at risk of ischaemic complications immediately after aneurysm surgery, when they were clinically stable. In each of these patients the clearance fell to lower levels prior to the development of ischaemia. The relationship between thermal clearance changes and established thresholds of cortical ischaemia require further investigation.

1 Gibbs FA. Proc Soc exp Biol (NY) 1933;31:141-6. 
INTRACRANIAL PRESSURE MONITORING IN THE ROUTINE ASSESSMENT OF PATIENTS WITH CRANIOSYNOSTOSIS USING THE CAMINO SYSTEM

WFJ Harkness, UB Andar, B Jones, RD Hayward. London

Since January 1990, 37 patients had intracranial pressure monitoring carried out as part of their assessment for newly diagnosed craniofacial anomalies. Patients with hydrocephalus or who had undergone previous surgery were not included in this study. The method employed was the Camino intracranial pressure monitoring system. The mean age of the patients monitored was 25 months with a range from two months to 11 years one month. The mean recording time was 20.9 hours. The procedure failed technically in four cases, all as a result of the bolts becoming dislodged, a technical failure rate of $10.8 \%$. Complications occurred in two cases $(5.4 \%)$ with no infection (1 seizure; 1 transient CSF leak after bolt removal).

Thirty four traces of longer than six hours duration were available for analysis. In 11 cases the resting pressure was over $15 \mathrm{mmHg}$ in a further 14 cases the resting pressure was between $10-15 \mathrm{mmHg}$, while the rest was below $10 \mathrm{mmHg}$. The sleeping record was analysed and this showed that in the group that had a resting pressure between 10 $15 \mathrm{mmHg}$, five patients experienced a sustained elevation of pressure above $15 \mathrm{mmHG}$. In only one patient who had a resting pressure below $10 \mathrm{mmHg}$ was the pressure elevated above $10 \mathrm{mmHg}$ during sleep.

The authors suggested that this technique was simple and safe to use and the information obtained valuable in the planning and timing of surgery.

WHAT HAPPENS TO CAPSULAR REMNANTS FOLLOWING REMOVAL OF ACOUSTIC NEUROMAS?

RH Lye, RT Ramsden, JE Gillespie, JE Dutton. Manchester

The fate of capsular fragments left attached to vital structures at the time of otherwise total removal of acoustic neuromas is unknown. Knowledge of the long term outcome for patients in whom such tiny fragments have been left in situ at operation may have important implications for patient care. This is particularly relevant in those instances where an attempt is made to preserve hearing. ${ }^{1}$ Of 21 patients in whom a small fragment of acoustic neuroma remained after operation, 14 agreed to have enhanced MRI using gadolinium diethylene-triamine-pentaacetic acid (GdDTPA), a mean of 70 months (range six months-12 years) after surgery. Such imaging improves tumour detection.

At review none of the patients had developed new symptoms or signs and CT had failed to demonstrate tumour recurrence. After Gd-DTPA enhanced MRI, persisting tumour rests were identified in seven patients and in four of these the remnant appeared to have gradually enlarged. The tumour fragment seemed more likely to persist if it was not cauterised at the time of operation.

1 Mattox DE. Otolarygol Clin North Am 1987;20:149-60.

2 Stack JP, Ramsden RT, Antoun NM, et al. Brit $J$ Radiol 1988;61:800-5.
PRESERVATION OF THE FACIAL NERVE DURING SURGERY FOR ACOUSTIC NEUROMA WITH CONTINUOUS ELECTROPHYSIOLOGICAI MONITORING

DA Jellinek, L Symon. London

Continuous EMG activity and responses to electrical stimulation of the facial nerve were monitored intraoperatively in 46 patients having primary removal of an acoustic neuroma. The rate of anatomical and functional preservation of the facial nerve of these patients was compared with a matched population where a facial nerve stimulator and monitoring of facial muscle contraction by the anaesthetist only was employed. Overall $93 \%(n=43)$ of facial nerves were preserved anatomically in patients with continuous EMG monitoring, compared with $64 \%(n=90)$ of patients $(n=140)$ without continuous monitoring. Among the 43 cases with anatomical facial nerve preservation, $65 \%(n=28)$ had immediate functional preservation. Immediate functional preservation was only achieved in $40 \%(n=36)$ of anatomically preserved facial nerves $(n=90)$ where conventional monitoring was used.

PREDICTING FACIAL NERVE FUNCTION AFTER SURGERY FOR ACOUSTIC NERVE TUMOUR: USE OF A NERVE STIMULATOR AND MONITOR PJ Kirkpatrick, G Watters, AJ Strong, JR Walker, MJ Gleeson. London

The use of intra-operative facial EMG was examined to assess facial nerve integrity during surgery for cerebello-pontine (CPA) angle tumours. Eighteen patients were grouped according to size of tumour ( 0 $2.5 \mathrm{~cm}-11$ cases; over $2.5 \mathrm{~cm}-7$ cases). The facial nerve was identified and integrity monitored throughout the operation by observing the EMG response to local bipola electrical stimulation ( $35 \mathrm{hz}$ ). Post-operative facial nerve function was graded according to the House Scale (follow up eight to 48 months). Tumour removal was complete in all cases. In patients with tumours up to $2.5 \mathrm{~cm}$, intra-operative facial nerve stimulation elicited a good EMG response in eight of the 11 cases, all of which regained good facial nerve function after operation (House Grades I and II). In the remaining three patients with small tumours, the EMG response was lost: two subsequently developed a moderately severe (Grade IV) dysfunction and the third a total paralysis (Grade VI). In the large tumour group, facial nerve stimulation indicated electrical integrity in three patients, two of whom developed moderate (Grade III) and the third, severe (Grade V) dysfunction. In the other four cases nerve function could not be detected at operation; three of these developed a moderate facial nerve dysfunction (Grade III/IV). Intra-operative facial nerve monitoring appeared to predict eventual facial function accurately only in the small tumour group. The monitoring system proved simple to use during surgery and is now regarded as an important aid to surgery for CPA tumours.

\section{MICROSURGICAL EXCISION OF}

PONTOMEDULLARY CAVERNOUS

HAEMANGIOMAS

A Jackowski, L Symon, D Bills. London

Although the natural history of cavernous haemangiomas (cavernomas) is incompletely understood, their tendency to present with spontaneous and repeated haemorrhages is well recognised. Brainstem cavernomas are fortunately rare as surgical treatment naturally carries considerable potential risk; the results of surgery have rarely been described. The authors reported their experience in treating seven patients with pontomedullary cavernomas that presented with one or more episodes of haemorrhage and followed for up to two years.

CT scans either demonstrated a haematoma or focal region of high density within the brainstem. Angiography failed to reveal abnormal vessels to the cavernoma. MRI was most useful in diagnosis and in demonstrating previous haemorrhages. An important observation was the finding of separate coexistent cerebellar medullary venous malformations (MVM) in two patients. Such an association needs to be recognised if haemorrhage or symptoms due to a cavernoma are not to be falsely attributed to an angiographically obvious MVM.

Evacuation of both haematoma and cavernoma was accomplished using standard microsurgical techniques. This was followed by significant improvement in neurological function in all patients.

BENIGN INTRINSIC TECTAL “TUMOURS” IN CHILDREN

PL May, S Blaser, RP Humphreys, DC Harwood-Nash, HJ Hoffman. Toronto

A specific group of intrinsic dorsal midbrain "tumours" in six children were identified by CT and MRI. Each patient presented with the symptoms of raised intracranial pressure (ICP) as a result of hydrocephalus due to obstruction of the sylvian aqueduct. No patient had brain stem signs referable to the tectal tumour or subsequently. All patients underwent cerebrospinal fluid (CSF) diversionary procedures. The radiological features were consistent and specific with four patients showing tectal calcification and no contrast enhancement on CT. MRI in all patients showed a focal tectal tumour distorting the collicular plate with no cystic components and increased signal intensity on the T2W images. There had been no evidence of progression with patient follow up of $1 \cdot 5,2.5$, $4 \cdot 5,5 \cdot 5,8$, and 17 years. CSF diversion had been the only surgical treatment and no patient received deep x-ray therapy (DXT). Five patients had normal intellectual development. In contrast to the majority of previously described periaqueductal and tectal tumours, this group appears to be truly benign. The authors suggested that patients presenting with these clinical and radiological features may be managed by CSF diversion, serial examination and MRI scanning alone.

COMPUTER GENERATED TITANIUM

CRANIOPLASTY-A PILOT STUDY

PJ McDermott, JM Joffe, A Linney, A Mosse, $M$ Harris. London

An outcome review of $\mathbf{4 0}$ cases of titanium cranioplasty fabricated from impressions taken of the patients' scalp showed that nine $(23 \%)$ were ill-fitting and $12(41 \%)$ of 29 frontal plates had a poor aesthetic result. The unsatisfactory results were attributable to difficulty ip defining defect borders, strains produced during insertion and inadequate communication between surgeon and prosthetist.

A pilot study of six cases fabricated from 
CT scan computer-generated models of cranial defects showed significant improvements. This method had the following advantages: patient-free procedure; well-defined defect margins and bone thickness to aid accurate plate design; improved aesthetic contour and orientation especially by mirror image reversal or superimposition of pre-operative scan; plate insertion was rapid because of accurate fit and, finally, potential for pre-operative osteotomy template and cranioplasty allowing one stage procedure.

The procedure of scanning, imaging, mould production, plate design and insertion was described.

COLLAGEN VICRYL MEMBRANE AS A NEW DURAL SUBSTITUTE

RN Meddings, $R$ Scott, $R$ Bullock, DA French, TAH Hide. Glasgow

No ideal dural graft is currently available. Many materials have been evaluated and lyophilised cadaveric human dura has become popular. Recently, this material has been putatively associated with CreutzfeldJacob disease.

The authors had evaluated a new collagencoated woven vicryl mesh previously used in urological repairs. Its "handling characteristics" and suture strength are superior to other substitutes.

In this study three degradable dural substitutes were compared: 1) collagen vicryl (Bovine collagen coated vicryl mesh); 2) Zenoderm (Porcine dermis); and 3) Lyodura (Lyophilised human cadaveric dura). Using a rabbit model the materials were implanted into $1.5 \mathrm{~cm}$ by $0.7 \mathrm{~cm}$ dural defects. In the control group the dura was excised but not replaced. Fifty five animals were used. They were killed at two, four, eight, 12 and 24 weeks after implantation, and the craniotomy was re-opened. The four groups were evaluated in two ways; 1 ) adhesions between the cortex and dura were graded and photographed; 2) the histological and macroscopic characteristics of the neomembrane was assessed in decalcified $H$ and $E$ stained whole cranium sections.

Collagen vicryl produced few adhesions to the cortex and was replaced by a neomembrane with good union to the host dura. In controls, no dural layer was formed and there were severe cortical adhesions. Zenoderm and Lyodura remained undegraded and produced more adhesions to cortex than collagen vicryl. Collagen vicryl supports ingrowth of fibroblasts and the production of a new collagen layer which resembled the original dura by three months. The other two dural substitutes were revitalised by host cells but remained undegraded at three months with ingrowth of woven bone and persistence of inflammatory and foreign body response.

Collagen vicryl is a suitable dural substitute with potential advantages over the other materials, and should be more fully evaluated, both in laboratory studies and clinically.

NEUROSURGICAL OPERATIVE CODING: PROBLEMS AND PROGRESS

RJ Nelson, J Ganley. Bristol

Medical audit, resource management and contracting - all demanded by recent changes in the organisation of the NHS-require timely, accurate collection and coding of primary data. The retrospective coding of operative procedures from hospital records and discharge summaries using the nationalstandard OPCS4 codes is slow, time-consuming and may result in significant errors. Clinicians can help overcome these problems by coding their own procedures postoperatively. Unfortunately their efforts are hampered by the cumbersome structure and inconsistencies of the OPCS4 codes. The authors had studied ways of improving operative coding by independent analysis of the annual work load of a regional neurosurgical unit and its coded returns and by nationwide surveys of coding practices using structured questionnaires. Using these studies a concise operative coding book had been drawn up which allows surgeons to code quickly and consistently. A nationally agreed neurosurgical operative coding book which clarifies the present OPCS4 codes and prepares for future improvements in coding would be desirable.

READMISSIONS TO A REGIONAL NEUROSURGICAL UNIT. A QUALITY ASSURANCE MEASURE? JD Palmer, PD Lees, JS Garfield, G NeilDwyer. Southampton

Quality assurance has become an essential part of neurosurgical practice. The Department of Health will increasingly apply a number of performance indicators in order to make comparisons between different units. Readmission rates may provide an outcome indicator allowing purchasers of care to make decisions on quality as well as cost. The readmission rates for the Wessex Neurological Centre were studied in the period January to December 1990 . In that period 1928 patients were admitted with 324 of these being readmissions. The notes were examined on those patients readmitted and the admission classified into avoidable or unavoidable groups. Comparisons were made between consultants within broad diagnostic groups. One hundred and forty four readmissions (7.5\% of total admissions) were classified as avoidable and $180(9 \cdot 3 \%)$ unavoidable. The diagnostic groups were discussed and comparisons made between the consultants practices. The results of this clinical audit were discussed as well as the validity of using readmission rates as an outcome indicator in neurosurgical practice.

\section{EXPERIENCE WITH THE HITCHCOCK}

STEREOTACTIC FRAME IN A REGIONAI

NEUROSURGICAL UNIT

N Kitchen, R Bradford. London

Unlike other commercially available stereotactic systems (for example, Leksell, BRW) there have been few reports, other than from the originators, of the use of the Hitchcock frame. The authors reported their initial experience with the first 50 cases on whom the system was used following its purchase in October 1989. Fifty five procedures were carried out; $49 \mathrm{CT}$-directed burr hole biopsies and three CT-directed craniotomies. All were performed under GA by the same surgeon (RB), the mean anaesthetic time being 96 minutes. Complications occurred in two patients (one haematoma, one death from brain swelling). A positive diagnosis was made in 48 cases $(96 \%)$ although in one a further biopsy was necessary. Therapeutic aspirations of tumour cysts and one brain abscess were also successfully performed. The authors found the Hitchcock frame to be a simple, low profile system which allowed for quick and reliable burr hole procedures. It was also convenient for stereotactic craniotomies as it left the operative field relatively unencumbered. The frame was scanner dependent and thus calculations were easy and an independent computer was not required. However, there had been technical problems with the biopsy needles and with the gantry fixation. In addition there had been some degradation of the hardware due to modern sterilising techniques.

\section{A MAGNETIC STEREOTAXIC SYSTEM}

MA Howard, MS Grady, RC Ritter, G Gillies. London, Seattle and Virginia, USA

Current CT techniques provide a detailed three dimensional map of the brain that is suboptimally utilised by many standard neurosurgical treatment methods. To improve on current techniques and expand the potential role of neurosurgery, a magnetic stereotaxic system (MSS) has been developed. ${ }^{12}$

The MSS enables non-invasive external manipulation of an intracerebral implant. Magnetic forces are exerted on the implant by an array of superconducting magnets. Radiographs define the implant position in relation to a preoperative MRI scan. A computer provides the surgeon with an image of the patient's brain, the location of the implant, and the option to move the implant in any direction desired.

Critical regions are avoided to arrive at precise locations deep in the brain. Potential clinical applications include: lesion making using a radiofrequency source to inductively heat the implant, and drug delivery to curvilinear structures such as the striatum.

Experiments in six anaesthetised dogs and four pigs have demonstrated that implants can be safely directed in three dimensions throughout the brain. Inductive heating of the implant creates well circumscribed lesions in the desired brain region. Human clinical studies using MSS delivered hyperthermia are currently under way in patients with gliomas, with the aim of destroying tumour cells by heat generated by the implant positioned within the confines of the tumour.

$$
\begin{aligned}
& 1 \text { Howard MA, Grady MS, Ritter RC, et al. } \\
& \text { Neurosurgery 1989;24:444-8. } \\
& 2 \text { Grady MS, Howard MA, Molloy JA, et al. } \\
& \text { Medical Physics 1989;16:263-72. }
\end{aligned}
$$

SHOULD THE NEUROSURGEON WEAR PROTECTIVE GLASSES?

K El-Shunnar. Edinburgh

The current debate among members of the medical profession has ruled out the possibility of obligatory HIV testing of al patients undergoing surgical procedures. With the impossible task of identifying all those high risk category patients, ${ }^{1}$ there is increasing concern among surgeons about contamination with patient's blood. ${ }^{2}$ With this in mind, the author, who does not normally wear glasses, conducted a pilot study where the need by the neurosurgeon to wear protective glasses in the operating theatre was evaluated.

Thirty consecutive neurosurgical procedures in which the author was involved in over a period of two months were looked at prospectively in relation to contamination of the surgeon's glasses at the end of the 
procedure. The results of this small study showed that there was a $100 \%$ risk of contamination with blood and or bone dust for the main surgeon performing the craniotomy and using a high speed drill. As an assistant the risk dropped to $50 \%$ for blood contamination and $\mathbf{8 0} \%$ for bone dust. Spinal surgery led to no contamination except where metal fixation was used and again this was attributed to the use of the high speed drill. Therefore it was recommended strongly that protective glasses should be used during craniotomy and whenever the high speed drill is used.

1 Expert Advisory Group on Aids. Guidance for clinical health care workers: protection against infection with HIV and Hepatitis viruses. UK Health Departments 1990:8-14.

2 Mishu B, Schaffiner W, Horan JM, et al. JAMA 1990;264:467-70.

A LATERAL APPROACH FOR VENTRALLY PLACED TUMOURS OF THE CRANIOVERTEBRAL JUNCTION G Kratimenos, HA Crockard. London

Tumours in this location are rare, presenting considerable difficulties of access and surrounded by the spinal cord/medulla, cranial and cervical nerves and important vessels. Meningiomas and neurofibromas are the commonest intradural tumours with the majority of them placed anterolaterally. Posterior and posterolateral approaches offer poor exposure which need considerable retraction to improve. Anterolateral approaches present limitations while the transoral approach, although effective in pure midline lesions, can be restrictive for ventrolateral tumours or broad-based meningiomas.

Anatomical dissections identified a possible lateral route, effected with exposure and mobilisation of the vertebral artery and allowing satisfactory exposure of the ventral spinomedullary surface and adequate visualisation of intradural vascular and nervous structures. The bone removal included a laterally placed retromastoid suboccipital craniectomy removing the lateral rim of the foramen magnum, the posterior third of the occipital condyle and lateral atlantal mass and part of the posterior arch of atlas. Complete removal was achieved of four meningiomas and two neurofibromas from five female and three male adult patients (aged 24 to 70 ) and of one eosinophilic granuloma from a boy aged eight who, because of extensive bone destruction, required addition bone grafting and halo immobilisation. Another patient had previously undergone cervical laminectomy and a transoral attempt without success.

No deaths were recorded while complications included a case of transient facial nerve palsy due to extracranial retraction and another of mild ipsilateral pyramidal weakness due to an ischaemic event. Both of them recovered rapidly. There were no cases of instability, CSF leak or infection. All patients improved with restoration of power, sensation and pain relief.

Important advantages of the approach include: excellent exposure of the ventral spinomedullary aspect, early and safe exposure of the vascular structures, preservation of stability, minimal risk for infection and CSF leak, elimination of need for retraction of the neuraxis and simplicity of instruments and technique. The results were excellent combining total tumour removal with minimal morbidity.
THE MANAGEMENT OF OCCULT SPINAL DYSRAPHISM: A REVIEW OF 49 PAEDIATRIC AND ADULT CASES

\section{KM Morris, GFG Findlay. Liverpool}

In recent years prophylactic surgery for all patients with occult dysraphism (OSD) has been advocated. ${ }^{1}$ Whilst this may be necessary for selected cases, the true incidence and natural history of OSD is unknown and therefore the ideal management for each patient is unclear and must be assessed individually.

The management of 22 children and 27 adults with occult spinal dysraphism (OSD) was reviewed. Patients presented in three groups: 1) childhood (CD), 2) secondary adult deterioration (SCAD)-a patient known to have dysraphism but to have been neurologically normal or stable for many years, and 3) primary adult deterioration (AD). A combination of compressive and tethering lesions were found more commonly in the adult group (AD). Surgery was mainly undertaken for rapid neurological deterioration or pain. Patients were otherwise carefully observed. Sensorimotor deficit $(83 \%)$ and pain $(78 \%)$ responded well to surgery. Urological function ( $20 \%$ ) responded poorly.

Certain groups such as children with lipomyelomeningocoeles may benefit from prophylactic surgery as may adults with mass lesions. Despite this the authors considered that there is still a case for conservative management in many cases.

1 Piatt JH, Hoffman HJ. Neuro-orthopaedics 1987; 3:67-75.

ACUTE PARAPLEGIA AS AN EXTREME

PRESENTATION OF ADULT TETHERED CORD SYNDROME IN A POST-MYELOMINGOCOELE PATIENT

AG Filler, JA Britton, D Uttley, HT Marsh. London

Thirty years ago, neurosurgeons began achieving substantial success in treating open myelomeningocoele, and the products of those successes are now presenting with unique adult problems which are late sequelae of the repairs. In a recent review of all published reports of adult onset tethered cord syndrome, only one of the 60 was a postmyelomeningocoele patient, although a second case has since been described.

The authors reported an additional 14 cases of adult tethered cord syndrome of which two occurred in post-myelomeningocoele patients. In both of the postmyelomeningocoele cases, the neurological deficits were characterised by acute, severe, remitting presentation without an obvious precipitating event. For example, a twenty two year old married, working mother, who had minimal gait deficit after perinatal repair of a low lumbosacral myelomeningocoele. She was transferred urgently from casualty, after suffering the sudden onset of complete paraplegia and near complete lower extremity sensory loss. CT myelography confirmed taut tethering of cord and roots. She had only modest improvement with dexamethasone. However, after laminectomy and release of tethered cord, she experienced rapid, dramatic recovery and walked out of the hospital without assistance one week after operation. Symptoms recurred eight months later but resolved with steriods alone.
ACUTE PARAPLEGIA AS AN EXTREME

PRESENTATION OF ADULT TETHERED CORD

SYNDROME IN A POST MYELOMINGOCOELE PATIENT

Panel discussion

Lively debate ensued with particular reference to pathophysiological mechanisms, different but uncertain natural histories of the various types, need for careful investigation including urodynamics and EMGs in asymptomatic patients, unpublished reoperation rates after prophylactic surgery, need for long term followup, postoperative imaging to audit correction of the anatomical problem and retethering.

A COMBINED SURGICAL APPROACH FOR RADICAL EXCISION OF SACROCOCCYGEAL TUMOURS. A REPORT OF FOUR RECENT CASES PO Byrne, IJ Robertson, RW Gullan, KM Anson, SA Andrews, AC Montgomery. London

Large sacrococcygeal tumours are rare and remain a difficult management problem. Chordomas are one of the commoner tumours encountered and may account for $30-40 \%$ of post-rectal/sacral tumours. However, they only represent $3-4 \%$ of primary bone tumours, which themselves are rare. They tend to be locally destructive and have malignant potential, having a well documented ability to metastasise. Nevertheless, local recurrence tends to be the greatest management problem.

Four consecutive cases were presented who had been managed in the last two years, aged 21 to 66 years; three were chordomas and one a schwannoma. Each was managed by a combined general and neurosurgical approach. Major radical excision of the tumour was attempted in all patients, involving high amputation of the sacrum and lower sacral nerve root division, as appropriate.

The authors suggested that these large lesions could be radically excised with limited postoperative morbidity and excellent preservation of neurological function, including sphincter control, provided one S2 root was left intact. Future management should be directed toward early diagnosis with the hope of achieving "cure".

THE HALIFAX INTERLAMINAR CLAMP SYSTEM: UK EXPERIENCE

P Statham, M O'Sullivan, T Russell. Edinburgh

The benefits and complications of the Halifax interlaminar clamp system had been evaluated by a retrospective patient review together with a postal questionnaire of nine other neurospinal centres known to have an interest in spinal surgery. Of the eight centres which replied, four were excluded due to limited experience (three patients or less). In the remaining five centres, the Halifax system was used in four or more patients (minimum four, maximum 31). In 44 patients it was inserted at $\mathrm{Cl} / 2$ and in one at $\mathrm{Cl} / 3$. Clamp failure was recognised in 14 of these patients due to loose screws in ten and unhooking of clamps in four. Nine needed a second operation because of occipital pain and/or instability. Complications occurred between one day and nine months after operation (median nine weeks). The indication for operation did not affect the frequency of clamp failure. 
In 24 patients the Halifax system was used below C3. No complication relating to insertion of the clamps developed in any of these patients.

The authors concluded that the Halifax interlaminar clamps are useful in posterior fixation at $\mathrm{C} 3$ or below. At $\mathrm{Cl} / 2$ they are unreliable, and need modification.

MANAGEMENT OF THORACOLUMBAR SPINAL TRAUMA WITH INCOMPLETE NEUROLOGICAL INJURY

ND Mendoza, R Bradford, J Lehovsky. London

The management of thoracolumbar fracture dislocation with incomplete neurological injury remains controversial. ${ }^{1}$ Adoption of a conservative approach with postural reduction and bed rest may yield good results but may lead to a significant incidence of late post traumatic painful spinal deformity. With the advent of one stage decompression and spinal fixation (using either an anterior or posterior approach or both) with intraoperative spinal cord monitoring ${ }^{2}$ it is possible to adopt a more aggressive policy to these injuries.

Nine patients (five male, four female with an age range of 16-48 years) had undergone spinal decompression and fixation. The spinal injuries consisted of four burst fractures of L1, two burst fractures of L3, one wedge fracture of $\mathrm{T} 5$, one wedge fracture of $\mathrm{T} 12$, and one burst fracture of L5. All patients had posterior short segment spinal fixation, with four patients having an additional anterior procedure, with intraoperative measurement of somatosensory evoked potentials. Five patients were in Frankel grade D preoperatively and of these, four have improved one grade postoperatively. Four patients were in Frankel grade $\mathrm{E}$ both pre- and postoperatively. The average total hospital stay from injury to discharge was 22 days.

Short segment spinal fixation ${ }^{3}$ and decompression allows immediate mobilisation of the patient reducing both the duration of hospital stay and rehabilitation and the incidence of late neurological deterioration and post traumatic kyphosis.

1 Davies WE, Morris JH, Hill V. J Bone Join Surgery Am 1980;62A:1324-8.

2 Loughnan BA, Hall GM. Br $J$ Anaesth 1989;63:587-94.

3 Dick W. Spine 1987;12:882-9.

THE NEUROSURGICAL IMPLICATIONS OF INTRACTIBLE EPILEPSY

JB Miles, PL May, D Smith, DW Chadwick. Liverpool

Although surgery for epilepsy has been practised for over one hundred years in the United Kingdom, there remains a large and ever increasing population of patients with intractable seizures who could potentially benefit from surgical intervention but who will never have access to this benefit. In 1989 there were approximately one hundred resective procedures for epilepsy carried out in the UK and estimates suggest a potential population of between two and ten thousand with a yearly accrual of six hundred in whom surgery for seizures may be appropriate. The management of this increasingly important problem must involve the establishment of skilled teams of specialists from diverse specialities working in a single unit where the development and teaching of the speciality can be continued. The Liverpool experience and protocol for the complex pre-surgical evaluation of these patients was presented. Particular reference was made to experience with WADA testing and use of Foramen Ovale electrodes. The authors presented the surgical options currently available and those that may need to be incorporated in the future, for example, radiosurgery, as well as the assessment of outcome. Finally, the problems implicit in taking a complex series of investigations down into the paediatric population were discussed with the hope that earlier surgery will result in lower morbidity and more prolonged benefit.

SURGERY FOR TEMPORAL LOBE EPILEPSY: PERSPECTIVE FROM PEROPERATIVE CORTICOGRAPHY AND TAILORED RESECTIONS AR Walsh, LM Ojemann, C Doderill, GA Ojemann

There is considerable variation of opinion on the most appropriate operative technique for the surgical treatment of temporal lobe epilepsy. Some surgeons have advocated procedures that resect predominantly or exclusively the medial temporal lobe structures; other groups concentrate on lateral temporal resection. The authors reported a retrospective review of 48 cases of temporal lobectomy for intractable epilepsy in which the extent of the medial and lateral resections was determined by peroperative corticography. Follow up was carried out five years after surgery: complete or near complete seizure control was obtained in 30 cases $(63 \%)$. Preresection corticography revealed a spike focus that was predominantly medial temporal in 27 cases $(59 \%)$, predominantly lateral temporal in six cases $(13 \%)$ and anterior inferolateral in 12 cases $(26 \%)$. Eight out of nine patients $(89 \%)$ without residual activity on post resection corticography obtained a good surgical result as opposed to only 19 of $35(54 \%)$ with residual activity suggesting this was of some predictive value. The extent of the medial and lateral resection has no effect on the surgical outcome suggesting that the procedures were correctly tailored with the corticography.

\section{STEREOTACTIC SELECTIVE AMYGDALO} HIPPOCAMPECTOMY - AN ALTERNATIVE APPROACH

MF Pell, DGT Thomas, SD Shorvon, DR Fish, SJM Smith. London

Anterior temporal lobectomy is the most commonly employed method for the surgical treatment of drug-resistant epilepsy where a lateralised temporal focus has been identified. A standard temporal lobe resection in the dominant hemisphere may have unacceptable morbidity. In such cases, selective amygdalohippocampectomy has developed as an alternative approach. The trans-sylvian route for amygdalophippocampectomy may be associated with moribidity related to vascular complications in the middle cerebral artery distribution. A lateral transcerebral approach using the Kelly-Goerss-Kall stereotactic CT directed apparatus offers an alternative method of selective amygdalohippocampectomy which does not expose the sylvian vessels.

Open stereotactic resection of the amygdala and hippocampus in the dominant hemisphere using the Kelly-Goerss-Kall apparatus had been used on four patients (mean age 23, 2 males: 2 females). All four patients had a cessation (2) or very marked reduction in seizure frequency (2) with minimal morbidity (one transient dysphasia and one transient VIth nerve palsy).

LUMBAR MICRODISCECTOMY: A LONG TERM

REVIEW OF THE FIRST 100 CASES

AJ Moore, D Uttley. London

Despite the high success rate of lumbar disc surgery in the short term, recent studies have called into question the benefits of surgical treatment in the long term. ${ }^{12}$ Lewis et al, showed a re-operation rate of $18 \%$ five to ten years after the initial discectomy. ${ }^{2}$

One hundred consecutive patients presenting with unilateral sciatica, with evidence of dural irritation and nerve root compression due to a radiologically proven lateral disc at a single level, were reviewed five to nine years after lumbar microdiscectomy. A number of outcome variables were assessed using either a patient questionnaire or direct contact. Nine patients had further surgery, and at operation seven of these were found to have further disc extrusions. Only one re-operation was performed more than six years after the initial surgery. Two further patients described symptoms suggestive of recurrence, but not sufficiently severe to consider further surgery, and $97 \%$ felt that surgery had been beneficial.

The results of this study would suggest that lumbar microdiscectomy not only provides short term symptomatic relief, but compares favourably with other techniques in terms of long term outcome.

1 Weber H. Spine 1983;8:131-40

2 Lewis PJ, Weir BKA, Broad RW, et al. J Neurosurg 1987;67:49-53.

\section{SURGICAL TREATMENT OF BRACHALGIA} M O'Sullivan, T Russell. Edinburgh

Brachalgia has been known as a complaint associated with cervical spondylosis since Lord Brain's monograph on this disease. Treatment of it has been the subject of controversy from groups who advocate either a posterior or anterior cervical approach to the lesion.

The authors presented a preliminary report of their series of 211 cases of brachalgia having their first operative procedure; the operative procedures used included anterior decompression, posterior decompression by either laminectomy or foraminotomy.

The authors conclude on the basis of their early results that surgical treatment of brachalgia appears to offer a good chance of resolution of the symptom and that a range of surgical procedures should be borne in mind when approaching the problem. Long term follow up of the complete cohort of patients was planned.

CT GUIDED LOCALISATION OF BRAIN TUMOURS M Tariq, AJ Kellerman. Romford, Essex

Accurate localisation of intracranial lesions is an essential prerequisite of any cranial neurosurgical procedure. Stereotactic frames utilising CT scanners have become standard in most units. Whilst the method is accurate it is time consuming. The authors reported a simple procedure. The patient was scanned in a routine manner. The slice which demonstrated the lesion most clearly was selected. 
The scanner table was then taken back to this slice and the position lights turned on. The position lights would be passing over the scalp at the tumour site. The surface of the scalp was then marked with a small aluminium disc which sealed the tops of the Urografin contrast medium. The patient was then re-scanned with a single slice at this level thus demonstrating the tumour and the marker on the same slice. The marker can then be adjusted to lie more directly over the tumour if required. Axial scans were usually sufficient but lesions near the vertex and in the occipital region were localised best by using coronal sections.

This method was most suitable for super- ficially placed tumours but was also helpful for the planning of all supratentoral craniotomies. It required no special equipment and complements other tumour localising methods. Experience with 60 patients was discussed. 